\title{
The Collapse of Yuan Dynasty from the Drinking Habit of the Mongolian
}

\author{
Jinyang Wang \\ Southwest Minzu University, Chengdu, China
}

Keywords: Mongolian; Excessive drinking; The collapse of Yuan Dynasty

\begin{abstract}
To study the various reasons for the collapse of Yuan Dynasty from the perspective of excessive drinking is the new point of view for the discussion of the decline of Yuan Dynasty, including the great impact of physical and mental health of the Mongolian and a large number of social and economic problems (which is related to the collapse of Yuan Dynasty in full flourish according to the author), and the worrying influence on the future of Mongolian nationality. This paper reviews the drinking history of Mongolian and considers the excessive drinking as important reasons for the collapse of Yuan Dynasty together with political, economic and national problems.
\end{abstract}

\section{Introduction}

As the old saying goes "no wine no seats, no wine no feast". The Mongolian like drinking with a long history of drinking for the Mongolian nationality, and drinking has been an integral part of their life. The hospitable Mongolian entertain guests with wine to show their respect for guests. Besides, they express their veneration for their ancestors and the universe by virtue of wine in important festivals, which is already a tradition and inherited by from generation to generation. The wine culture matters significantly in their cooking culture of Mongolian, as entertainment for their leisure and recreation and the link of communication in all activities. However, the Mongolian lacks basic constraints on drinking, thus, excessive drinking is common in their society, which has serious impact on all aspects of the life and irreparable loss impeding their life, thus, it is urgent to correct the negative social atmosphere. This paper analyzes the excessive drinking of Mongolian, and the relationship with the collapse of Yuan Dynasty, finds out problems and puts forward suggestions on solutions.

\section{Various drinking customs}

\subsection{Drinking in royal court}

The royal court of Yuan Dynasty attached importance to drinking and consumed a large quantity of wine in important festivals. Within seven days after the Xianzong, Mongke Khan ascending the throne, the feasts in royal court were held continuously with innumerable wine and meat, which can be called "Lucullian banquets". According to rulers of Yuan Dynasty, wine banquet is the way to be connected to courtiers, the reward to subjects from the court and the bounties bestowed, which is significant for sustaining the rule with the aid of connection between emperors and courtiers. In addition, wine feast is also an important part of national ceremonies and the manifestation of court etiquette. Therefore, since the beginning of Yuan Dynasty, wine feast has gradually become a tradition and an indispensable part of festivals with special meaning such as ascending the throne, all kinds of ceremonies, diplomacy and etc., whereas, excessive drinking and subsequent serious social problems occur. Under the leadership of rulers, Yuan Dynasty was filled with extravagant atmosphere. Rulers presented a state of drunkenness in the "Lucullian banquets" all day long, not caring for the people's suffering nor national affairs; administrative officials are mostly Mongolians, and according to their customs, drinking is a normal thing. They do not think about the consequences, also indulged in wine together with rulers, which leads to a lazy state for the entire country. The rulers enjoyed peace, thinking that the dynasty lasted forever. Officials do not care about their jobs, lack the most basic understanding of social issues, and do not work. The rulers consider wine as bounties bestowed to courtiers inside and outside the court, which was a common 
phenomenon. Li qixian wrote "Wine in tin pot containing the smell of rain and dew, Pair of court brocade showing the brilliance of rosy clouds" to express the mellifluence wine bestowed by emperor and the delicacy of wine vessel; Chen Yiji recorded "Fairy wine with good taste is the dew of the heaven, Delicate port from the court is the spring in the early December" to show his gratitude for the ruler and his loyalty with "Court wine in silver pot, royal soup in jade cup, A tiny drop from the monarch, loyalty heart from me”. It can be seen that people bestowed are gratitude for the rulers, and the purpose of connecting courtiers and civilian from wine feast bestowed is reached to some extent, which strengthens the loyalty of courtiers and civilian to emperors and matters positively for sustaining the status of rules. The Mongolians are from grasslands and are ethnic groups on horseback. Their source of livelihood depends mainly on grazing, and the weather has a great impact on grazing. If they encounter storms and other major natural disasters, their income will be greatly reduced a lot or even to nothing. Therefore, in the long-term environment of relying on the weather, Mongolians have formed the veneration for the nature, they respect the world, and wine is "the essence of food," which can be used as a sacrifice, especially the kumiss, Mongolian special drinks, which was most used in the worship of Yuan dynasty, reflected in historical records, such as "Whatever the great sacrificial offerings, the kumiss, especially transported in leather packet by the producer from the royal Taibusiqi is the priority". Like other dynasties, Yuan Dynasty formulates a series of norms and regulaitons with complicated court etiquette and selection method of wine vessel and the number of wine servants. For instance, there are 60 guests in drinking feast, service for wine, kumiss and food counts one-third respectively, proven in "Pleasure in the court, grand etiquettes in the feast. Announcement in entertaining drinking.” Besides, Yuan Dynasty is influenced a lot by the Jin Dynasty with many traditions shown in drinking customs, like "accompanying drinking", in which the emperor is drinking in chorus of wine servants, "Instrument in left hand and wine in right hand, busy in accompanying drinking. Back late in dusk, clothes and incense left", which also shows the impact of wine culture on the court of Yuan Dynasty.

\subsection{Civilian drinking}

\subsubsection{Incessant toasting}

The Mongolian people are great-hearted and hospitable. Kumiss is their best specialty for entertaining guests, as the best communication emotions between people. They make friends in drinking, and the wine culture has been integrated into their life with the beautiful wine aroma. The passion of Mongolians for wine is beyond our imagination, which is an inseparable necessity for their daily lives. In the gathering area of Mongolian, the pleasure of spending time and life with friends is the most typical thing. Will such a nation greatly develop? Will there be a bright future for the nation? Who would expect them to value their self-cultivation and construction for rejuvenation?

\subsubsection{Violence in drinking}

It is noted that in the Mongolian wine culture, violence also goes subsequently. Once they drink too much, "alcohol makes men brave", the people who are coward would behave without thinking and taking care of the consequences and begin to make trouble. Besides, most of Mongolian are brave with wild nature in their blood, which causes fighting and violence in large Mongolian banquets, and inharmoniousness from time to time. Minor events probably eventually result in giant conflicts and contradictions. The wine destroys the cooperation between the Mongolian. Under the imagination, inevitable, the wine feast will end up with violence.

\section{Wine ruins the Yuan Dynasty}

\subsection{Excessive drinking brings incessant politic crisis}

The excessive drinking of rules of Yuan Dynasty is common and continuous, according to History of Yuan, "Emperors all addictive to alcohol, drinking excessively with courtiers everyday", 
which depicts the daily life of the second rule of Yuan Dynasty, Taizong, Gedei Khan who has already been addictive to drinking. However, this is absurd phenomenon that a ruler is drinking every day and abandoning state affairs. Based on the phenomenon and state status, Yelu Chucai persuaded that "Wine has negative impact on everything, even iron, not to mention physical health." After some consideration, the rule realized that daily excessive drinking is inappropriate and criticized himself, believed that he did not undertake the responsibility of a ruler and was addictive to alcohol. Whereas, the rule still die of excessive drinking. In the whole Yuan Dynasty, from the first founder to the last ruler, no one avoids drinking and draws a lesson from ancestors. For instance, Kublai Khan still drink when he is sick and get disease in feet for a lifetime, and even a mastered doctor can do nothing for his disease; the disease of Ding Zonggui also cannot be controlled because of excessive drinking; Chengzong, Tie Muer ignored beat and scold, physical pain cannot discourage him from stealing wine; Wuzong, Haishan praised wine as beautiful concubines; the last ruler Shundi was ambitious in his youth, however, he still drank like his ancestors and ruined Yuan Dynasty. In the whole Yuan Dynasty, rulers addicted to wine are countless, and it is already unbelievable for them to hold for several decades. The collapse of Yuan Dynasty is on the peril of rulers, and the impact of wine cannot be ignored at the same time.

\subsection{Extravagance and corruption of Yuan Dynasty from wine vessel}

The mellifluence and unique charm of wine can be strengthened by delicate wine vessel, which is shown clearly in drinking culture of the rulers of Yuan Dynasty. The rulers of Yuan Dynasty who are addicted to wine produced delicate and expensive wine vessel, and set wine pool and wine sea for high-level enjoyment. For the luxury of the drinking of Mongolian rulers, Marco Polo, who had traveled to Europe and Asia, was shocked. He saw beautifully crafted hollow cabinet-shaped wine vessel in the court that was about one meter long and wide, vivid animals carved on the surface of the wine vessel, and there is a large bowl inside which can hold a barrel of wine, four small pots around, and wine vessels that can hold share of wine for 8 to 10 people, called bail. For Marco Polo, the luxury of drinking in the Yuan court has reached a climax, the unimaginable delicacy of wine vessel. For instance, as for the "unholy jade sea" inherited from the Yuan Dynasty, which is now kept in Yuwengting in Tuancheng Park in Beijing, the white lines on the surface are like waves, fish and beasts hidden on it, so the extravagance of drinking in Yuan court can be imagined. The Yuan court also gave some exquisite wine vessels as honors to the courtiers who had merit. For example, the Yuan court rewarded the vessels made of gold and silver for Chahan who had military merits. During the period of Mongolia Yuan, the wine industry was developed and the variety of wines greatly increased, and yellow rice wine, fruit wine, liquor and cooking wine were developed. The Principles of Correct Diet records a wide variety of wines in Yuan Dynasty. Apart from daily drinking, they also have wine for different uses, such as tonic wine which has a nourishing effect on the human body, and can enhance people's physique with long-term moderate amount. In the expenditure on consumption of Yuan court, wine occupies a considerable proportion, which has created great financial pressure on the Yuan court. Moreover, the Yuan court has no clear understanding of its financial situation and is indulged in drinking all day. The expenditures has not been reduced in the slightest, but continuously increasing when revenues did not increase then. The goal of "opening sources and cutting down on expenditure" cannot be achieved, which eventually leads to the obstruction. Eventually, the economy of Yuan court is on the verge of collapse. The rulers of Yuan Dynasty did not meet ends meet, did not recognize their problems in the payment imbalance and the constant natural and man-made disasters, and finally perished in the crusade of the people, which is the lesson that the rulers of the Mongolian should learn, inevitable in the historical development.

\section{Personality of Mongolian reflected from drinking habit}

Korshinwi once said that it is more likely that ambitious people are addicted to alcohol. When their ambitions cannot be realized in reality, not willing to be degraded into unaccomplished people, and there is no approach for them to display their own talent, nowhere to express their frustration, 
so they choose alcohol to drink down sorrow, and exert all the passion and ambition in the fond dream. The Mongolian people are ethnic groups on horseback, started with riding and conquer the world with military force. However, after they established the Mongolian Yuan regime, they lost the goal of moving forward and did not know where the road to the future. The confused psychology made Yuan court lost in wine so they anesthetize themselves through wine and express their unparalleled spirit in wine.

The Mongolian, as a nomadic nationality with unstable economic source of life, has developed strong aggression in the fight against the nature for a long time. They established the country by virtue of military force and did not change their aggressive character after the establishment of power, retained their original living habits, sniffed at the Central Plain Culture and oppressed the Han people. They present only the image of a barbarian ruler for descendants, lack of enterprise, which also forecasted the destruction of the Yuan court.

From the drinking culture of the Mongolian people, it can be seen that the Mongolians' mentality has been in a state of arrogance, they are always self-centered, and have not had the slightest idea of learning from other cultures, lack of method of interaction with others, advocating violence and respecting the military, which embodies the immaturity in the national personality. The establishment of the Mongolian Yuan Dynasty was an aggression of the backward nomadic civilization on the Central Plain Culture, accompanied by violence during the seizure of political power and during the political power, which ultimately led to the collapse of Yuan Dynasty. The drinking habit is an important component of its collapse because it affects the health of Mongolians and their intelligence.

\section{References}

[1] A Sigen. The Relation between the Drink Habit of Mongolian and Body and Heart Dangerous of Nation [J]. Journal of Inner Mongolia University for Nationalities (Social Sciences), 2009.

[2] Yang Yinmin. Empire on Drink: The Wine Industry and Society in Yuan Dynasty [J]. Tianjin: Tianjin Chinese Classics Publishing House, 2009.

[3] Yang Yinmin. On Wine Custom and Wine Policy in Yuan Dynasty [D]. Heibei: Heibei Normal University, 2003.

[4] Ha Sichaolu. Modern Thinking on Admonition of Alcohol Avoiding by Genghis Khan [J]. Collected Papers of Clean Government Culture by Genghis Khan, 2013.

[5] Shi Lili. A Research on Social Factors about History of Mongolian Kumiss Technology [D]. Inner Mongolia: Inner Mongolia University, 2010. 